\section{Diabetes and corneal endothelial cell characteristics: a study based on Eye Bank data}

\author{
Geoffrey Brown, ${ }^{1}$ Eric Siegel, ${ }^{2}$ \\ Steve Staples, Jennifer Doyle, ${ }^{1}$ \\ Jason Y. Chang ${ }^{3,4}$
}

${ }^{1}$ Arkansas Lions Eye Bank and laboratory; 2Department of Biostatistics;

${ }^{3}$ Department of Neurobiology and

Developmental Sciences; ${ }^{4}$ Department

of Ophthalmology, Jones Eye Institute, University of Arkansas for Medical

Sciences, Little Rock, AR, USA

\section{Abstract}

The aim of the article is to determine whether corneal endothelial cell density and other characteristics, such as cell area, pleomorphism and polymegathism, are affected by diabetes. Corneal endothelial cell density and other characteristics of donor eyes collected during 2007 and 2008 in a local Eye Bank were measured by the HAI Eyebank Specular Microscope System. Adult donors aged 21 or older who consented to research were divided into healthy versus compromised eye-status groups based on eye disease or past eye surgeries. Differences in corneal measures between diabetic and non-diabetic subjects were analyzed separately in each group via Mixed Models ANCOVA, with Diabetes as the fixed effect, Donor as the random effect, and Age as the continuous covariate. A total of 253 subjects met study criteria, of which 81 (32\%) had diabetes. In the 180 subjects with healthy eye status, the medians (ranges) of age were 62 (29-78) years among 52 diabetics (29\%), versus 57 (21-79) years among non-diabetics $(\mathrm{P}=0.013)$. In the 73 subjects with compromised eye status, the medians (ranges) of age were 70 (32-78) years among 29 diabetics (40\%), versus 70 (29-79) years among nondiabetics $(\mathrm{P}=0.77)$. Between diabetics and non-diabetics, eye disease and past eye surgeries were well-balanced in the compromised eye-status group, while race and sex were wellbalanced in both eye-status groups. Results from separate analyses on the two groups indicated that diabetes did not affect corneal cell density or other corneal-cell characteristics analyzed. Even though diabetics constituted a large percentage of the Eye Bank donor population, this disease did not have a statistically significant impact on corneal endothelial cell density, cell area, pleomorphism or polymegathism.

\section{Introduction}

Since the first successful corneal transplant performed in $1905,{ }^{1}$ there is a constant need for more donor eyes for this procedure. As such, there were 39,391 corneal transplants performed in the United States in 2007, and the number increased to 41,652 in 2008 according to the record provided by the Eye Bank Association of America (EBAA). ${ }^{2}$

Corneal endothelial cell density is one of the most important criteria that determine whether a donor cornea is eligible for transplant. There is an age-dependent decrease of corneal endothelial cell density, a phenomenon that has been documented in people from various ethnic groups. Examples include those from the United states, ${ }^{3,4}$ Japan, ${ }^{4}$ India, ${ }^{5}$ Philippine, ${ }^{6}$ Pakistan, ${ }^{7}$ Iran, ${ }^{8}$ and China. ${ }^{9}$ However, it is important to note that all of the reports above are data derived from normal, healthy volunteers. Very often people with a history of diabetes mellitus were excluded. As a result, the data presented in those reports do not necessarily reflect those from donor eyes in a typical Eye Bank. This is because a typical Eye Bank does encounter donors with various health conditions, including diabetes, and can be very different from those normal, healthy volunteers reported in those studies.

Exclusion of people with diabetes in those reports analyzing corneal endothelial cell density implies that diabetes can alter corneal cell density. However, the published literature on this subject contains conflicting results. Diabetes is reported to increase, ${ }^{10}$ decrease ${ }^{11-13}$ or have no effect ${ }^{14-17}$ on corneal endothelial cell density.

In this study, we used data collected from 253 research-consenting adults who donated their corneas to a local Eye Bank during 2007 and 2008 to examine whether there was evidence suggesting that diabetes might adversely affect corneal endothelial qualities such as endothelial cell density. To do this, we classified donors into two groups, a healthy group and a group with compromised eye status, based on history of eye disease or past eye surgeries. We then compared the age-adjusted impact of diabetes on four corneal cell parameters: cell density, cell area, pleomorphism, and polymegathism in each group. The percentage of hexagonal cells was used as an indicator of pleomorphism and the coefficient of variation in cell size was used as an indicator of polymegathism.

\section{Materials and Methods}

Data of this report were extracted from the Arkansas Lions Eye Bank and laboratory (the
Correspondence: Jason Y. Chang, Department of Neurobiology and Developmental Sciences, Slot 510, University of Arkansas for Medical Sciences 4301 W. Markham St., Little Rock, AR 72205, USA. Tel. +1.501.686.7025 - Fax: +1.501.686-6382.

E-mail: changjasony@uams.edu

Key words: corneal endothelial cells, diabetes, Eye Bank.

Acknowledgements: this work was partially supported by funds from Research to Prevent Blindness. We greatly appreciate Eye Bank donors who not only donated their corneas but also allowed us to conduct this research. The thoughtful critiques and suggestions provided by Dr. Michael Brown are highly appreciated.

Contributions: GB, SS, JD, data collection and assistance in manuscript writing; ES, data analysis and assistance in manuscript writing; JYC, organizer of the project, data analysis and the main writer of the manuscript.

Conflict of interest: the authors report no conflicts of interest.

Received for publication: 14 June 2011. Accepted for publication: 12 September 2011.

This work is licensed under a Creative Commons Attribution NonCommercial 3.0 License (CC BYNC 3.0).

(C) Copyright G. Brown et al., 2011

Licensee PAGEPress, Italy

Eye Reports 2011; 1:e9

doi:10.4081/eye.2011.e9

Eye Bank) housed at the University of Arkansas for Medical Sciences, which routinely obtained informed consent from individual donors for use of their eyes in research. The consent included the authorization to share personal health information recorded in the Medical/Social History Questionnaire for research. This Eye Bank received donor eyes from 154 individuals (113 male, 41 female) in 2007 and 156 individuals (91 male, 65 female) in 2008. For comparison, the total number of donors in 2004, 2005 and 2006 was 181, 183 and 148, respectively. Among donors in 2007 and 2008, 275 adults aged 21 years or older allowed the Eye Bank to use their data for research. Specimens from this group were excluded from further processing if they were of poor conditions, if the donors had positive serology for viruses such as HIV or hepatitis, or if the donors had a history of other medical conditions that were deemed to pose a risk to corneal-transplant recipients. A total of 501 corneas from 253 donors were eventually examined on the specular microscope, from which this report was generated.

The HAI Eyebank Specular Microscope System (Hightech American Industrial 
Laboratories, Inc., Lexington, MA, USA) was used to document corneal characteristics. Approximately 100 cells of each cornea were analyzed, and the computer automatically calculated corneal endothelial cell density, polymegathism and pleomorphism for each specimen. The mean cell area (in $\mu \mathrm{m}^{2} /$ cell) of each specimen was calculated as 1,000,000 divided by its corneal-cell density (in cells $/ \mathrm{mm}^{2}$ ).

According to the Eye Bank record, 73 (29\%) of the 253 study subjects had various types of eye diseases (e.g., cataract, glaucoma, macular degeneration) or eye operations (e.g., intraocular lens, trauma repair, shunt, corrective surgery). In the past, people with these conditions were excluded from studies analyzing the effect of diabetes on corneal endothelial cell density because these conditions could potentially affect one or more of the parameter studied. ${ }^{2-15,17,18}$ In our study, a preliminary analysis was conducted for confounding of eye disease and eye surgeries with diabetes and age. Because of the results, subjects were classified as having compromised eye status if they had eye disease or a history of eye surgeries, versus having healthy eye status if they had neither, and the two eye-status groups were analyzed separately in parallel analyses, as described in the next section.

\section{Statistical analyses}

In the preliminary analysis for confounding, the associations of age with eye disease and eye surgeries were tested using the Wilcoxon rank sum (WRS) test, while the associations of diabetes with eye disease and eye surgeries were tested using the Pearson chi-square test; the magnitude of all associations were quantified using Spearman's rank-correlation coefficient. Within each eye-status group, donor ages were summarized by diabetes status (yes/no) as the median (range), and tested for imbalance via WRS test, while race and sex were summarized by diabetes status as proportions, and tested for imbalance via Fisher's exact test. Within the compromised eye-status group, the incidence of eye disease, intra-ocular lens (IOL) surgeries, and non-IOL surger- ies were summarized by diabetes status as proportions, and tested for imbalance using Fisher's exact test. Corneal-cell measures were summarized by eye status and decade of age as means and standard deviations (SDs). Left eyes were compared to right eyes via paired ttest for possible differences in corneal measures. The impact of diabetes on corneal measures was conducted in separate, parallel analyses on the two eye-status groups using mixedmodels analysis of covariance (ANCOVA), ${ }^{19}$ with Diabetes as the fixed effect, Donor as the random effect, and Age as the continuous covariate. The validity of ANCOVA models were pre-tested via mixed-models regression techniques, specifically by testing for significant age-by-diabetes interactions. Following the practice of Ray and Rosner, ${ }^{21}$ inter-eye correlations (IECs) were estimated as intra-class correlations (ICCs) from the mixed-models variance components, using the following formula:

$$
\mathrm{ICC}=\frac{\sigma_{b}^{2}}{\sigma_{b}^{2}+\sigma_{w}^{2}}
$$

where $\sigma_{b}^{2}$ denotes the variance between donors, $\sigma_{w}^{2}$ denotes the variance within donors, and their sum denotes the total variance. To help interpret the diabetes effects biologically, predicted reference means were calculated for a reference age of 60 years in the healthy eye-status group and 70 years in the compromised eye-status group; both reference ages were chosen to be near the medians of their groups. Finally, the question was investigated of whether the age trends, age-adjusted diabetes effects, or total variances and IECs differed significantly between subjects with healthy versus compromised eye status. To do this, the data for each corneal-cell measure from the two groups were combined into a single mixed-models analysis that contained an eye-status main effect plus eye-status interactions with age and diabetes. Eye-status differences in the age trends and diabetes effects were tested for significance using the Type-III
F-statistics for the eye-status interactions with age and diabetes, respectively. Eye-status differences in the total variances and IECs were tested for significance via likelihood-ratio chisquare test of the full model (having different variance components between groups) against a reduced model (having equal variance components between groups). An alpha $=0.05$ significance level was used for all statistical tests.

\section{Results}

\section{Donor characteristics}

Among a total of 310 donors in 2007 and 2008 , a total of 275 adults 21 or older (134 in 2007 and 141 in 2008) gave informed consent to participate in research. Of these, 22 had their specimens excluded from processing because of poor condition, positive viral serology, or medical history for conditions that put a transplant recipient at risk. Of the remaining 253 subjects, 73 (29\%) were classified as having compromised eye status (eye disease or a history of eye surgeries), while 180 (71\%) were classified as having healthy eye status (no eye disease and no history of eye surgeries). A total of 81 subjects in the study (32\%) had diabetes.

The preliminary analysis for confounding showed (i) that eye disease was associated strongly with age (rank correlation 0.40; WRS $\mathrm{P}<0.0001$ ) and mildly with diabetes (rank correlation 0.12 ; chi-square $\mathrm{P}=0.06$ ), (ii) that eyesurgery history was associated strongly with age (rank correlation 0.38; WRS $\mathrm{P}<0.0001$ ) and moderately with diabetes (rank correlation 0.16; chi-square $\mathrm{P}=0.01$ ), and (iii) that eye-surgery history had high association with eye disease (rank correlation 0.72 ; chi-square $\mathrm{P}<0.0001$ ). Because of the evident confounding, we chose to study the two eye-status groups in separate, parallel analyses.

Table 1 gives breakdowns of donor characteristics by diabetes status within the two eyestatus groups. In adults with healthy eye status, the median age was 62 years for diabetics

Table 1. Donor characteristics by diabetes status.

\begin{tabular}{|c|c|c|c|c|c|c|c|}
\hline & Diabetic & $\begin{array}{l}\text { In adults witl } \\
\text { althy eye sta } \\
\text { Nondiabetic }\end{array}$ & P* & Diabetic & $\begin{array}{l}\text { In adults with } \\
\text { romised eye } \\
\text { Nondiabetic }\end{array}$ & P* & Overall \\
\hline Donor number & 52 & 128 & --- & 29 & 44 & --- & 253 \\
\hline Median age (range) & $62(29-78)$ & 57 (21-79) & 0.013 & $70(32-78)$ & $70(29-79)$ & 0.77 & $62(21-79)$ \\
\hline Non-Caucasian & $5(10 \%)$ & $6(5 \%)$ & 0.30 & $1(3 \%)$ & $2(5 \%)$ & 1.00 & $14(6 \%)$ \\
\hline Female & $13(25 \%)$ & $42(33 \%)$ & 0.37 & $12(41 \%)$ & $17(39 \%)$ & 1.00 & $84(33 \%)$ \\
\hline Any eye disease & $0(0 \%)$ & $0(0 \%)$ & --- & $28(97 \%)$ & $40(91 \%)$ & 0.64 & $68(28 \%)$ \\
\hline Any non-IOL surgery & $0(0 \%)$ & $0(0 \%)$ & --- & $5(17 \%)$ & $3(7 \%)$ & 0.25 & $8(3 \%)$ \\
\hline Any IOL surgery & $0(0 \%)$ & $0(0 \%)$ & --- & $21(72 \%)$ & $25(57 \%)$ & 0.22 & $46(18 \%)$ \\
\hline
\end{tabular}

*P values are via Wilcoxon rank-sum test on Age, and via Fisher's exact test on all other donor characteristics. 
versus 57 years for non-diabetics $(\mathrm{P}=0.013)$; however, the age distributions still overlapped substantially, with ranges of 29-78 years for diabetics versus 21-79 years for non-diabetics. In adults with compromised eye status, the median age was 70 years for diabetics versus 70 years for non-diabetics $(\mathrm{P}=0.77)$. Race and sex showed no significant diabetes imbalance in either eye-status group, and the incidences of eye diseases and past eye surgeries showed no significant diabetes imbalance in the compromised eye-status group.

\section{Corneal endothelial-cell measures of each eye status group}

Left eyes were compared to right eyes via paired t-test for significant differences in corneal epithelial-cell measures; none were found (all $\mathrm{P}>0.50$ ). Table 2 shows descriptively how corneal cell density $\left(\right.$ cells $\left./ \mathrm{mm}^{2}\right)$, cell area ( $\left.\mu \mathrm{m}^{2} / \mathrm{cell}\right)$, pleomorphism ( $\%$ of cells that are hexagonal), and polymegathism (coefficient of variation in cell size) varies with age and eye status. Both eye-status groups show similarly decreasing trends with age in cell density, similarly increasing trends with age in cell area, and similarly unclear trends with age in pleomorphism and polymegathism.

\section{Age-adjusted diabetes effect in adult donors with healthy eye status}

The corneal-cell measures of adult donors with healthy eye status were analyzed for ageadjusted diabetes effects using mixed-models regression techniques. None of the age trends had a significant quadratic component, indi- cating that it was reasonable to fit all corneal measures with linear trends. All age-by-diabetes interactions were non-significant, indicating for each measure (i) that the linear trends had the same slope for diabetics versus non-diabetics, and therefore (ii) that mixedmodels ANCOVA was the appropriate analysis model. Table 3 shows the results of the mixedmodels ANCOVAs on subjects with healthy eye status. Inter-eye correlations ranged from a low of $26.4 \%$ for pleomorphism to a high of $69.7 \%$ for cell density. The age effect was highly significant $(\mathrm{P}<.0001)$ with positive slope for cell area, highly significant $(\mathrm{P}<.0001)$ with negative slope for cell density, but insignificant for pleomorphism $(\mathrm{P}=0.63)$ and polymegathism $(\mathrm{P}=0.24)$. The age-adjusted diabetes effects were statistically insignificant

Table 2. Corneal cell measures versus age group and eye status.

\begin{tabular}{|c|c|c|c|c|c|c|}
\hline Age group & Eye status & \# of eyes* & Cell density ${ }^{\circ}$ & Cell area ${ }^{\#}$ & Pleomorphism $^{\S}$ & Polymegathism ${ }^{\$}$ \\
\hline \multirow[t]{2}{*}{$21-30$} & Healthy & 30 & 3019 (258) & $333.7(29.0)$ & $54.47(7.14)$ & $19.47(3.31)$ \\
\hline & Compromised & 2 & $2918(74)$ & $342.9(8.7)$ & $54.50(0.71)$ & $19.00(1.41)$ \\
\hline \multirow[t]{2}{*}{$31-40$} & Healthy & 24 & 3072 (451) & $330.7(37.8)$ & $55.58(6.90)$ & $18.50(3.05)$ \\
\hline & Compromised & 3 & $2979(105)$ & $336.0(11.6)$ & $60.67(2.52)$ & $16.67(0.58)$ \\
\hline \multirow[t]{2}{*}{$41-50$} & Healthy & 56 & $2662(293)$ & $380.2(42.1)$ & $52.46(7.19)$ & $19.19(4.84)$ \\
\hline & Compromised & 4 & 2605 (123) & $384.5(18.9)$ & $50.50(3.87)$ & $16.00(1.63)$ \\
\hline \multirow[t]{2}{*}{$51-60$} & Healthy & 94 & $2706(319)$ & $375.8(56.0)$ & $52.91(7.08)$ & $20.05(5.68)$ \\
\hline & Compromised & 18 & 2791 (279) & $361.6(34.8)$ & $53.33(6.52)$ & $21.11(3.20)$ \\
\hline \multirow[t]{2}{*}{$61-70$} & Healthy & 106 & $2627(230)$ & $383.6(34.7)$ & $52.52(6.10)$ & $19.83(3.21)$ \\
\hline & Compromised & 44 & $2392(453)$ & 440.9 (131.) & $50.55(7.24)$ & $21.59(4.03)$ \\
\hline \multirow[t]{3}{*}{$71-80$} & Healthy & 50 & $2530(404)$ & $406.9(76.9)$ & $54.32(6.76)$ & $20.08(2.58)$ \\
\hline & Compromised & 70 & $2413(452)$ & $429.7(87.3)$ & $51.30(6.87)$ & $21.51(3.59)$ \\
\hline & Average of all groups & $2639(389)$ & $388.8(72.4)$ & $52.76(6.86)$ & $20.12(4.12)$ & \\
\hline
\end{tabular}

Data from both eyes of the same individual were used to calculate the mean (SD) of the group. ${ }^{*}$ Measurements were available on a total of 501 eyes from 253 subjects. ${ }^{\circ} \mathrm{Cell}$ density, average density of cells in the

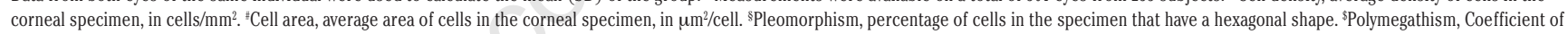
variation of cell size in the corneal specimen, in percentage units.

Table 3. Mixed-models ANCOVAs for diabetes effect adjusting for age, conducted on adult donors with healthy eye status.

\begin{tabular}{|c|c|c|c|c|c|c|}
\hline $\begin{array}{l}\text { Corneal cell measure } \\
\text { (units) }\end{array}$ & $\begin{array}{l}\text { Total variance } \\
\text { (IEC)* }\end{array}$ & Effect name & Estimate $\pm \mathrm{SE}^{\circ}$ & DF & $\begin{array}{c}\mathrm{t} \\
\text { statistic }\end{array}$ & $P$ \\
\hline $\begin{array}{l}\text { Cell area } \\
\left(\mu \mathrm{m}^{2} / \text { cell }\right)\end{array}$ & $\begin{array}{c}2512.1 \\
(62.1 \%)\end{array}$ & $\begin{array}{c}\text { Age }^{\sharp} \\
\text { Diabetes }^{\S} \\
\text { (reference means) }^{\S}\end{array}$ & $\begin{array}{c}+1.36 \pm 0.24 \\
-7.64 \pm 7.60 \\
(384.46 \pm 4.26)^{\wedge} \\
(376.82 \pm 6.26)^{* *}\end{array}$ & $\begin{array}{l}179 \\
179\end{array}$ & $\begin{array}{c}+5.61 \\
-1.01 \\
-\end{array}$ & $\begin{array}{c}<.0001 \\
0.32 \\
-\end{array}$ \\
\hline $\begin{array}{l}\text { Cell density } \\
\left(\text { cells } / \mathrm{mm}^{2}\right)\end{array}$ & $\begin{array}{r}101899 \\
(69.7 \%)\end{array}$ & $\begin{array}{c}\text { Age }^{\sharp} \\
\text { Diabetes }^{\S} \\
\text { (reference means) }^{\S}\end{array}$ & $\begin{array}{c}-9.71 \pm 1.58 \\
+38.8 \pm 49.6 \\
(2650.3 \pm 27.7)^{\wedge} \\
(2689.0 \pm 40.8)^{* *}\end{array}$ & $\begin{array}{l}179 \\
179\end{array}$ & $\begin{array}{l}-6.16 \\
+0.78 \\
-\end{array}$ & $\begin{array}{c}<.0001 \\
0.43 \\
-\end{array}$ \\
\hline Pleomorphism (\%) & $\begin{array}{l}46.355 \\
(26.4 \%)\end{array}$ & $\begin{array}{c}\text { Age\# } \\
\text { Diabetes }^{\S} \\
\text { (reference means) }^{\$}\end{array}$ & $\begin{array}{c}-0.014 \pm 0.029 \\
-0.402 \pm 0.913 \\
(53.287 \pm 0.512)^{\wedge} \\
(52.885 \pm 0.751)^{* *}\end{array}$ & $\begin{array}{l}178 \\
178\end{array}$ & $\begin{array}{r}-0.48 \\
-0.44 \\
-\end{array}$ & $\begin{array}{c}0.63 \\
0.66 \\
-\end{array}$ \\
\hline Polymegathism (\%) & $\begin{array}{c}17.601 \\
(37.2 \%)\end{array}$ & $\begin{array}{c}\text { Age }^{\#} \\
\text { Diabetes }^{\S} \\
\text { (reference means) }^{\S}\end{array}$ & $\begin{array}{c}+0.022 \pm 0.019 \\
+0.103 \pm 0.586 \\
(19.766 \pm 0.328)^{\wedge} \\
(19.869 \pm 0.482)^{* *}\end{array}$ & $\begin{array}{l}179 \\
179\end{array}$ & $\begin{array}{l}+1.18 \\
+0.18 \\
-\end{array}$ & $\begin{array}{l}0.24 \\
0.86 \\
-\end{array}$ \\
\hline
\end{tabular}

*Inter-eye correlation between left and right eyeballs from the same donor; ${ }^{\circ}$ Standard Error of the estimate. ${ }^{\sharp}$ Slope of the linear age trend, in units/year, for subjects in the healthy eye-status group. ${ }^{\circledR}$ Age-adjusted differ-

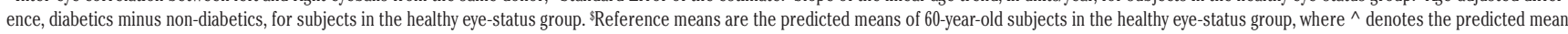
of the non-diabetic 60 -year-old and * denotes the predicted mean of the diabetic 60 -year-old. Reference means double as Y-intercepts in the regression equations $Y=$ Reference + Slope $x$ (Age -60 ), where $Y$ is the corneal-cell measure, Age is the subject's age in years, Slope is the slope of the linear age trend, and Reference is the reference mean denoted by ${ }^{\wedge}$ and ${ }^{* *}$ for non-diabetics and diabetics, respectively. 
(lowest $\mathrm{P}=0.32$, cell area) on all four cell measures. Table 3 also shows the ANCOVA models' predicted reference means for two 60 -year-old individuals with healthy eye status, one with diabetes and one without, in order to facilitate biological interpretation of the diabetes effects. Computations from the values in Table 3 show that the reference diabetic had 2.0\% lower cell area, $1.5 \%$ higher cell density, $0.7 \%$ lower pleomorphism, and $0.5 \%$ higher polymegathism than did the reference non-diabetic. It should be noted that the reference means in Table 3 double as Y-intercepts in the regression equations $\mathrm{Y}=$ Reference + Slope $\mathrm{x}$ (Age 60 ), where $Y$ is the predicted mean corneal-cell measure, Age is the subject's age in years, Slope is the slope of the linear age trend, and Reference is the appropriate reference mean for diabetics or non-diabetics with healthy eye status. Graphic illustration of the results for cell density is shown in Figure 1.

\section{Age-adjusted diabetes effect in adult donors with compromised eye status}

The corneal-cell measures of adult donors with compromised eye status were likewise analyzed for age-adjusted diabetes effects using mixed-models regression techniques. Again, none of the age trends had a significant quadratic component, indicating that it was reasonable to fit all corneal measures with linear trends. And again, all age-by-diabetes interactions were non-significant, indicating for each measure (i) that the linear trends had the same slope for diabetics versus non-diabetics, and therefore (ii) that mixed-models ANCOVA was the appropriate analysis model. Table 4 shows the results of the mixed-models ANCOVAs on subjects with compromised eye status. Inter-eye correlations ranged from a low of $24.9 \%$ for cell area to a high of $51.7 \%$ for cell density. The age effect was statistically significant $(\mathrm{P}=0.0075)$ with positive slope for cell area, highly significant $(\mathrm{P}=0.0017)$ with negative slope for cell density, insignificant $(\mathrm{P}=0.10)$ for pleomorphism, and statistically significant $(\mathrm{P}=0.010)$ with positive slope for polymegathism. The age-adjusted diabetes effects were statistically insignificant (lowest $\mathrm{P}=0.19$, pleomorphism) on all four cell measures. Table 4 also shows the ANCOVA models' predicted reference means for two 70-year-old individuals with compromised eye status, one with diabetes and one without, in order to facilitate biological interpretation of the diabetes effects. Computations from the values in Table 4 show that, compared to the reference non-diabetic, the reference diabetic had 2.1\% higher cell area, $3.6 \%$ lower cell density, $3.4 \%$ lower pleomorphism, and $3.0 \%$ higher polymegathism. Here, the reference means in Table 4 double as Y-intercepts in the regres-

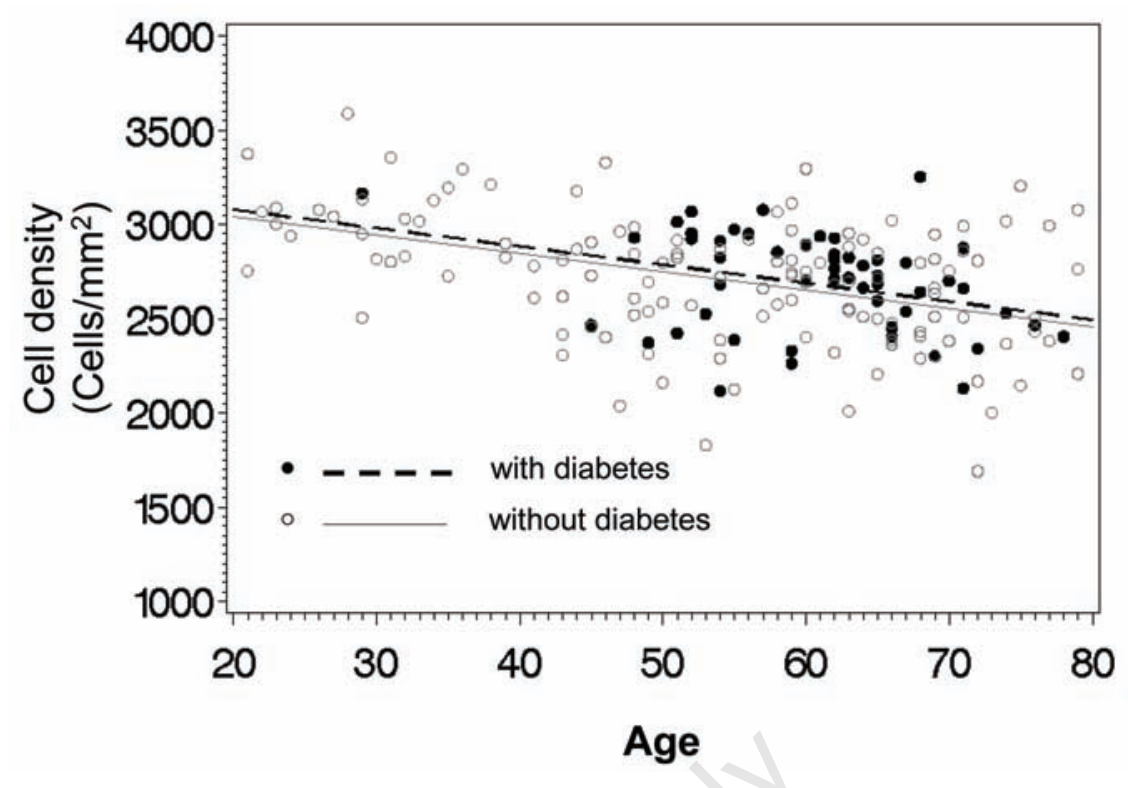

Figure 1. Corneal endothelial cell density as a function of age in donors with healthy eye status. Vertical axis shows cell density in cells $/ \mathrm{mm}^{2}$, while horizontal axis shows age in years. Solid black circles (dashed black line) represent observed values (predicted means) of cell density in diabetics, while open gray circles (solid line) represent observed values (predicted means) of cell density in non-diabetics. The regression equation for diabetics (dashed black line) is: Cell Density (in cells $\left./ \mathrm{mm}^{2}\right)=2689.0-9.71 \times$ (Age - 60), where Age is in years. The regression equation for non-diabetics (solid gray line) is: Cell Density (in cells $\left./ \mathrm{mm}^{2}\right)=2650.3-9.71 \times($ Age -60$)$, where Age is in years.

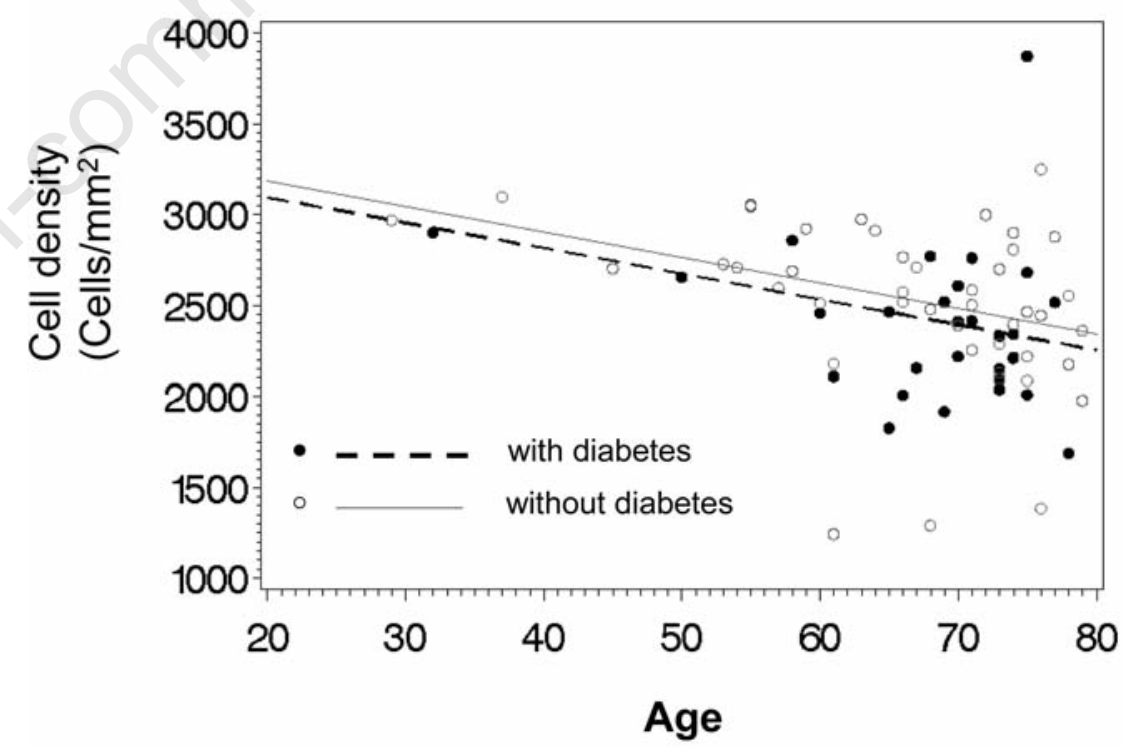

Figure 2. Corneal endothelial cell density as a function of age in donors with compromised eye status. Vertical axis shows cell density in cells $/ \mathrm{mm}^{2}$, while horizontal axis shows age in years. Solid black circles (dashed black line) represent observed values (predicted means) of cell density in diabetics, while open gray circles (solid line) represent observed values (predicted means) of cell density in non-diabetics. The regression equation for diabetics (dashed black line) is: Cell Density (in cells $\left./ \mathrm{mm}^{2}\right)=2392.1-14.05 \mathrm{x}$ (Age -70 ), where Age is in years. The regression equation for non-diabetics (solid gray line) is: Cell Density (in cells $\left./ \mathrm{mm}^{2}\right)=2482.3-14.05 \times($ Age -70$)$, where Age is in years. 
sion equations $\mathrm{Y}=$ Reference + Slope $\mathrm{x}$ (Age 70 ), where $Y$ is the predicted mean corneal-cell measure, Age is the subject's age in years, Slope is the slope of the linear age trend, and Reference is the appropriate reference mean for diabetics or non-diabetics with compromised eye status. Graphic illustration of the results for corneal cell density is shown in Figure 2.

\section{Differences between ANCOVA- model results for subjects with healthy versus compromised eye status}

Although the focus of this report is on the age-adjusted diabetes effect, it is reasonable to ask whether subjects having compromised eye status (Table 4) differed significantly from subjects having healthy eye status (Table 3 ) with respect to the age trend or age-adjusted diabetes effect in any corneal-cell measure. We investigated this question by combining the data for each corneal-cell measure from the two groups into a single mixed-models analysis, as described in the Statistical Analysis section. For polymegathism, the difference in age trends between Tables 3 and 4 was almost significant (interaction $\mathrm{P}=0.07$ ), but for the other three measures, the differences in age trends between tables was not significant (lowest interaction $\mathrm{P}=0.18$ ). And none of the four corneal-cell measures showed a statistically significant difference in their diabetes effect between the two tables (lowest interaction $\mathrm{P}=0.21$ ).

However, likelihood-ratio chi-square tests showed that, when compared to subjects with healthy eye status, those with compromised eye status had significantly larger between- donor and within-donor variances for both cell area and cell density. This finding reinforces the appropriateness of the decision to conduct separate analyses on subjects with healthy versus compromised eye status. For cell area, between-donor variance increased to 1.5 -fold and within-donor variance increased to 7.5fold, such that total variance increased to 3.8fold (9565.0 divided by 2512.1) while IEC fell by 37.2 percentage points $(62.1 \%$ versus $24.9 \%)$ from Table 3 to Table $4\left(\chi^{2}=150.9, \mathrm{DF}=2\right.$; $\mathrm{P}<0.0001)$. For cell density, a similar analysis indicates that between-donor variance increased to 1.3-fold and within-donor variance increased to 2.8 -fold, such that total variance increased to 1.8 -fold (180,845 divided by 101,899) while IEC fell by 18.0 percentage points (69.7\% versus $51.7 \%)$ from Table 3 to Table $4\left(\chi^{2}=36.05, \mathrm{DF}=2 ; \mathrm{P}<0.0001\right)$. On the other hand, the total variance and IEC showed very little change between tables for pleomorphism (chi-square $=0.14, \mathrm{DF}=2 ; \mathrm{P}=0.93$ ), and a suggestive, but insignificant change between tables for polymegathism (chi-square $=4.81$, $\mathrm{DF}=2 ; \mathrm{P}=0.090$ ).

\section{Discussion}

Corneal endothelial cell density from Eye Bank donors was previously examined by the Cornea Donor Study using 1101 qualified donor cornea collected from January 10, 2000 to August 2, 2002. ${ }^{22}$ These investigators noticed a non-linear age-dependent drop of cell density until age 60 . Beyond this point, the cell density changed little. It should be noted that only corneas qualified for that particular study were used in that analysis, which meant that all corneas analyzed in that report had a cell density between $2300-3300$ cells $/ \mathrm{mm}^{2} .^{22}$ In contrast, our data included 253 research-consenting adult donors during years 2007 and 2008. Consequently, ours reflected the raw data that one would encounter in a typical regional Eye Bank. Results from this study indicated that there was an age-dependent decrease of corneal endothelial cell density in both eye-status groups (Tables 3 and 4). It should be noted that, among those donors at $>70$ years old, $\sim 73 \%$ (88 out of 120 eyes) met the standard $\left(\geq 2,300\right.$ cells $\left./ \mathrm{mm}^{2}\right)$ set by the Cornea Donor Study. Thus, age alone should not be used as a criterion for donor cornea. In practice, our Eye Bank uses 2000 cells $/ \mathrm{mm}^{2}$ as the cutoff criterion to determine whether the cell density of a donor cornea is qualified for transplant.

According to data provided by the NIH (year 2007), $10.7 \%$ (23.5 million) of the population in the United States age 20 years or older have diabetes. The prevalence of diabetes increased to $23.1 \%$ (12.2 million) of the population age 60 years or older. ${ }^{23}$ Our data from 2007 and 2008 indicated that $\sim 32 \%$ of our adult donors had diabetes, which was significantly higher than the $18 \%$ reported in the Cornea Donor Study that involved 1,101 corneas..$^{22}$ Importantly, $\sim 38 \%$ of donors among those 60 years or older in our study population had diabetes. This was much higher than the abovementioned 23.1\% in the United State. Based on the report from the Arkansas Department of Health and Human Services, ${ }^{24}$ an estimated 233,255 adult residents in Arkansas had diabetes in 2005. The cost of hospital charges was $\sim 87$ million for Arkansas in 2005, which included 651 lower extremity amputations and

Table 4. Mixed-models ANCOVA of diabetes effect adjusting for age, conducted on adult donors with compromised eye status.

\begin{tabular}{|c|c|c|c|c|c|c|}
\hline $\begin{array}{l}\text { Corneal cell measure } \\
\text { (units) }\end{array}$ & $\begin{array}{l}\text { Total variance } \\
\text { (IEC)* }\end{array}$ & Effect name & Estimate $\pm \mathrm{SE}^{\circ}$ & $\mathrm{DF}$ & $\stackrel{\mathrm{t}}{\text { statistic }}$ & $P$ \\
\hline $\begin{array}{l}\text { Cell area } \\
\left(\mu \mathrm{m}^{2} / \text { cell }\right)\end{array}$ & $\begin{array}{c}9565.0 \\
(24.9 \%)\end{array}$ & $\begin{array}{c}\text { Age }^{\#} \\
\text { Diabetes }^{\S} \\
\text { (reference means) }^{\$}\end{array}$ & $\begin{array}{c}+2.50 \pm 0.91 \\
+8.71 \pm 18.72 \\
(422.65 \pm 12.19)^{\wedge} \\
(431.36 \pm 14.55)^{* *}\end{array}$ & $\begin{array}{l}68 \\
68 \\
-\end{array}$ & $\begin{array}{l}+2.76 \\
+0.47 \\
-\end{array}$ & $\begin{array}{c}0.0075 \\
0.64 \\
-\end{array}$ \\
\hline $\begin{array}{l}\text { Cell density } \\
\left(\text { cells } / \mathrm{mm}^{2}\right)\end{array}$ & $\begin{array}{l}180845 \\
(51.7 \%)\end{array}$ & $\begin{array}{c}\text { Age }^{\#} \\
\text { Diabetes } \\
\text { (reference means) }\end{array}$ & $\begin{array}{c}-14.05 \pm 4.29 \\
-90.2 \pm 89.4 \\
(2482.3 \pm 58.2)^{\wedge} \\
(2392.1 \pm 69.5)^{* *}\end{array}$ & $\begin{array}{l}68 \\
68 \\
-\end{array}$ & $\begin{array}{r}-3.27 \\
-1.01 \\
- \\
-\end{array}$ & $\begin{array}{c}0.0017 \\
0.32 \\
-\end{array}$ \\
\hline Pleomorphism (\%) & $\begin{array}{c}46.786 \\
(31.3 \%)\end{array}$ & $\begin{array}{c}\text { Age }^{\#} \\
\text { Diabetes }^{\S} \\
\text { (reference means) }^{\$}\end{array}$ & $\begin{array}{c}-0.108 \pm 0.065 \\
-1.773 \pm 1.341 \\
(52.068 \pm 0.874)^{\wedge} \\
(50.295 \pm 1.043)^{* *}\end{array}$ & $\begin{array}{l}68 \\
68 \\
-\end{array}$ & $\begin{array}{r}-1.66 \\
-1.32 \\
-\end{array}$ & $\begin{array}{l}0.10 \\
0.19 \\
-\end{array}$ \\
\hline Polymegathism (\%) & $\begin{array}{c}13.240 \\
(42.9 \%)\end{array}$ & $\begin{array}{c}\text { Age }^{\sharp} \\
\text { Diabetes } \\
\text { (reference means) }^{\$}\end{array}$ & $\begin{array}{c}+0.094 \pm 0.036 \\
+0.644 \pm 0.743 \\
(21.182 \pm 0.484)^{\wedge} \\
(21.827 \pm 0.578)^{* *}\end{array}$ & $\begin{array}{l}68 \\
68\end{array}$ & $\begin{array}{l}+2.63 \\
+0.87 \\
-\end{array}$ & $\begin{array}{c}0.010 \\
0.39 \\
-\end{array}$ \\
\hline
\end{tabular}

*Inter-eye correlation between left and right eyeballs from the same donor; ${ }^{\circ}$ Standard Error of the estimate. ${ }^{*}$ Slope of the linear age trend, in units/year, for subjects in the compromised eye-status group. ${ }^{\circledR}$ Age-adjusted difference, diabetics minus non-diabetics, for subjects in the compromised eye-status group. ${ }^{*}$ Reference means are the predicted means of 70-year-old subjects in the compromised eye-status group, where $\wedge$ denotes the predicted mean of the non-diabetic 70-year-old and ** denotes the predicted mean of the diabetic 70-year-old. Reference means double as Y-intercepts in the regression equations Y $=$ Reference + Slope $\mathrm{x}$ (Age -70 ), where $\mathrm{Y}$ is the corneal-cell measure, Age is the subject's age in years, Slope is the slope of the linear age trend, and Reference is the reference mean denoted by ^ and ${ }^{* *}$ for non-diabetics and diabetics, respectively. 
1565 hospitalizations for ketoacidosis.

This high prevalence of diabetic donors raised an important question, i.e., whether this disease can affect corneal endothelial cell quality, including cell density, thus compromising the number of qualifying corneas. This issue becomes even more important when we consider that the number of qualified corneas received in each Eye Bank may decrease because more and more refractory corneal procedures are being currently performed. ${ }^{25}$ The effect of diabetes on corneal endothelial cells was indeed a subject of discussion in several reports. Based on a comparison of 30 diabetic patients and 30 non-diabetic subjects using contact specular microscope, Siribunkum, et al. reported that the diabetics had statistically significant increase in corneal endothelial cell density and decrease in mean cell area. ${ }^{10} \mathrm{~A}$ comparison of 158 type II diabetic patients and 165 control subjects led Mathew, et al. concluded that type II diabetes caused an increase $(\sim 5 \%)$ of corneal endothelial cell density. ${ }^{26}$

The finding of an increased endothelial cell density was not supported by other reports. For example, Lee et al. conducted an age-adjusted comparison of 200 diabetics to 100 normal subjects, and found that that diabetics had statistically significantly less $(\sim 5 \%)$ cell density as compared to controls (diabetes: $2577 \pm 27$, control: $2700 \pm 39$ ). They also found that diabetics had more irregular shaped cells and more variation in cell sizes. ${ }^{12}$ Modis, et al. ${ }^{27}$ recently reported that there was a statistically significant decrease $(\sim 3 \%)$ in endothelial cell density in type I diabetes relative to healthy subjects ( $2428 \pm 219$ versus $2495 \pm 191)$. However, they did not find a statistically significant difference in endothelial cell density between type II diabetes and age-matched controls. An earlier study by Inoue et al. using a multivariate regression analysis comparing 99 diabetics and 97 control subjects also found that diabetics had lower endothelial cell density. ${ }^{11}$

In contrast to those reports above, other studies found diabetes did not cause statistical differences in corneal endothelial cell density. Larsson, et al. analyzed 49 type I diabetics, 60 type II diabetics and their respective agematched controls and found there was no difference in endothelial cell density between diabetics and control subjects. ${ }^{15}$ Pardos and Krachmer studied 52 diabetic patients with long-term ( $>14$ years) proliferative retinopathy also found no evidence that diabetes caused statistically significant difference in endothelial cell density when compared to 32 control subjects. ${ }^{14}$ Finally, Inoue, et al. examined a group of 1394 cataract patients before their surgery procedures and found that the presence of type 2 diabetes had no effect on endothelial cell density in this particular group of patients. ${ }^{18}$ Results from this study indicated that diabetes did not cause statistically differ- ent endothelial cell density (Tables 3,4; Figures $1,2)$, cell area, pleomorphism and polymegathism (Tables 3,4), regardless of eye status.

Given our findings that corneas from diabetic donors are comparable to those from nondiabetic donors and are appropriate for cornea transplant, an important issue is whether corneas from diabetic donors perform as well as those from non-diabetic donors after the transplant surgery. This issue is important because a recent report by Mathew, et al. indicated that surgeries that affect cornea, such as manual small incision cataract surgery, could cause a decrease in corneal endothelial cell density, and this decrease appeared to be more pronounced in type II diabetic patients. ${ }^{26}$ Based on this finding, there is a possibility that corneas from diabetic donors may behave differently compared to those from non-diabetic donors. We currently do not have data to address this issue and will investigate this in future studies.

This current study was unique in two ways. While data from live volunteers reported in those above-mentioned reports were valid, they did not necessarily represent the population encountered in an Eye Bank. In contrast, this study was unique in that it represented the actual data from a regional Eye Bank where donor corneas were collected and shipped out routinely for corneal transplants. Second, while other studies were performed in subjects without eye diseases and eye surgeries, we performed two parallel analyses on those with and those without compromised eye conditions. The same conclusion was achieved in both analyses.

There were certainly some limitations to this study. First, it represented a set of 2-year data from an Arkansas Eye Bank. This could be used to compare data from Eye Banks in other regions (e.g., Alaska, Maine or Florida) or other countries (e.g., France, Guatemala or Australia) but it was not necessarily a fair representation of what they would encounter in those Eye Banks. Second, this study used a closed pool of donors. Instead of a continuous recruitment of volunteers to reach a certain target number (e.g., 100 diabetics and 100 controls), we used data from donors within a 2year period and had no control over how many subjects we would have in each category. Also, there was a screening process of the potential donors before we collected their corneas. Those did not meet our criteria were rejected, thus their data were not used for this analysis. Furthermore, we were limited to use only data from those donors who consented to our research. In this regard, we were fortunate to have $\sim 94 \%$ of adult donors who gave informed consent to use their data for research.

An additional limitation we encountered in carrying out this project was that we obtained the information regarding diabetes from the
Medical/Social History Questionnaire, which gave us a positive identification of diabetic donors but was limited such that it was without detailed disease history for each individual. We do not have a detailed record of type I versus type II diabetes for each donor. As a result, we grouped both types together in the analysis. Consequently, we could not conclude whether type I diabetes was significantly different from type II diabetes for those parameters we evaluated in this study. In a report analyzing corneal endothelial cells in patients with type I and type II diabetes, Modis, et al. concluded that type I diabetic corneas were more susceptible to environmental changes than type II corneas. ${ }^{27}$ Based on their findings, there is a possibility that corneas from type I and type II diabetic donors may perform differently after the transplant. This issue warrants further investigation in the future.

In conclusion, we performed a study on data collected from the Arkansas Lions Eye Bank and laboratory during 2007 and 2008. In findings similar to those of other studies, we observed among subjects with healthy eye status (Table 3 ) an age-dependent decrease in corneal endothelial cell density and an age-dependent increase in cell area, along with statistically insignificant age trends in percentage of hexagonal cells and coefficient of variation in cell size. Among subjects with compromised eye status (Table 4), we observed statistically significant age-dependent decrease in cell density as well as increase in cell area and variation in cell size. The age trend for percentage of hexagonal cells was not significant. Importantly, subjects with compromised eye status had significantly larger variance components for cell density and cell area; for both measures, the difference was especially pronounced for the component of variance between eyeballs within the same donor. This finding suggests that previous studies ${ }^{12-15,17,18}$ were prudent to have excluded subjects with eye disease or past eye surgeries. Also importantly, there was a large percentage of donors who had diabetes: $32 \%$ overall, $29 \%$ among subjects with healthy eye status and $40 \%$ among subjects with compromised eye status. Differences in corneal measures between diabetic and non-diabetic subjects were analyzed in both eye-status groups via separate, parallel mixed-models ANCOVAs. Results indicated that, when adjusted for age, diabetes did not have a statistically significant impact on corneal endothelial cell density, cell area, pleomorphism and polymegathism, either in subjects with healthy eye status, or in subjects whose status was compromised by eye disease or history of eye surgeries. Based on the parameters analyzed in this study, corneas from diabetic donors were comparable to those from non-diabetic donors for cornea transplants. Future analysis is required to determine whether the outcomes of corneal transplant are comparable from corneas 
obtained from diabetic and non-diabetic donors, and whether corneas from type I and type II diabetic donors perform equally well after the transplant.

\section{References}

1. Moffatt SL, Cartwright VA, Stumpf TH. Centennial review of corneal transplantation. Clin Experiment Ophthalmol 2005;33: 642-57.

2. EBAA. Eye Bank Association of America Press Release (April 24, 2009). http://www.restoresight.org/files/2008pres srelease_statreport.pdf Accessed: 22 September 2009.

3. Yee RW, Matsuda M, Schultz RO, Edelhauser HF. Changes in the normal corneal endothelial cellular pattern as a function of age. Curr Eye Res 1985;4:671-8.

4. Matsuda M, Yee RW, Edelhauser HF. Comparison of the corneal endothelium in an American and a Japanese population. Arch 0phthalmol 1985;103:68-70.

5. Rao SK, Ranjan Sen P, Fogla R, et al. Corneal endothelial cell density and morphology in normal Indian eyes. Cornea 2000;19:820-3.

6. Padilla MD, Sibayan SA, Gonzales CS. Corneal endothelial cell density and morphology in normal Filipino eyes. Cornea 2004;23:129-35.

7. Ashraf KM, Saeed MU, Zia R. Corneal endothelial cell density in a normal Pakistani population. Eye (Lond) 2006;20:116-8.

8. Hashemian MN, Moghimi S, Fard MA, et al. Corneal endothelial cell density and morphology in normal Iranian eyes. BMC Ophthalmol 2006;6:9.

9. Yunliang S, Yuqiang H, Ying-Peng L, et al. Corneal endothelial cell density and morphology in healthy Chinese eyes. Cornea 2007;26:130-2.

10. Siribunkum J, Kosrirukvongs P, Singalavanija A. Corneal abnormalities in diabetes. J Med Assoc Thai 2001;84:1075-83.

11. Inoue $\mathrm{K}$, Kato $\mathrm{S}$, Inoue $\mathrm{Y}$, et al. The corneal endothelium and thickness in type II diabetes mellitus. Jpn J Ophthalmol 2002;46: 65-9.

12. Lee JS, Oum BS, Choi HY, et al. Differences in corneal thickness and corneal endothelium related to duration in diabetes. Eye (Lond) 2006;20:315-8.

13. Roszkowska AM, Tringali CG, Colosi P, et al. Corneal endothelium evaluation in type I and type II diabetes mellitus. Ophthalmologica 1999;213:258-61.

14. Pardos GJ, Krachmer JH. Comparison of endothelial cell density in diabetics and a control population. Am J Ophthalmol 1980; 90:172-4.

15. Larsson LI, Bourne WM, Pach JM, Brubaker RF. Structure and function of the corneal endothelium in diabetes mellitus type I and type II. Arch Ophthalmol 1996; 114:9-14.

16. Matsuda M, Ohguro N, Ishimoto I, Fukuda M. Relationship of corneal endothelial morphology to diabetic retinopathy, duration of diabetes and glycemic control. Jpn J Ophthalmol 1990;34:53-6.

17. Quadrado MJ, Popper M, Morgado AM, et al. Diabetes and corneal cell densities in humans by in vivo confocal microscopy. Cornea 2006;25:761-8.

18. Inoue K, Tokuda Y, Inoue $Y$, et al. Corneal endothelial cell morphology in patients undergoing cataract surgery. Cornea 2002;21:360-3.

19. Littell RC, ed. SAS System for Mixed Models. 4th ed. Analysis of Covariance. Cary, NC: SAS Institute; 1996. pp. 171-227.

20. Ray WA, O'Day DM. Statistical analysis of multi-eye data in ophthalmic research. Invest Ophthalmol Vis Sci 1985;26:1186-8.

21. Rosner B. Statistical methods in ophthalmology: an adjustment for the intraclass correlation between eyes. Biometrics 1982;38:105-14.

22. Sugar A, Gal RL, Beck W, et al. Baseline donor characteristics in the Cornea Donor Study. Cornea 2005;24:389-96.

23. National Diabetes Statistics, 2007 fact sheet. National Institute of Diabetes and Digestive and Kidney Diseases. U.S. Department of Health and Human Services, National Institutes of Health. http://diabetes.niddk.nih.gov/dm/pubs/statistics/ Accessed: 22 September 2009.

24. Seaton D. Diabetes: The burden of diabetes in the Natural State. 2007. http://www.healthy.arkansas.gov/programs Services/epidemiology/ChronicDisease/Do cuments/publications/diabetes_report200 7.pdf Accessed: 22 September 2009.

25. Chu W. The past twenty-five years in eye banking. Cornea 2000;19:754-65.

26. Mathew PT, David S, Thomas N. Endothelial cell loss and central corneal thickness in patients with and without diabetes after manual small incision cataract surgery. Cornea 2011;30:424-8.

27. Modis L Jr, Szalai E, Kertesz K, et al. Evaluation of the corneal endothelium in patients with diabetes mellitus type I and II. Histol Histopathol 2010;25:1531-7. 